OPEN ACCESS

Edited by:

Alessio Avenanti,

Università di Bologna, Italy

Reviewed by:

Carlos Tomaz,

Universidade Ceuma, Brazi Douglas Watt,

Boston University School of Medicine,

United States

Sandra Baez,

Institute of Cognitive Neurology,

Argentina

*Correspondence:

César F. Lima

cesar.lima@iscte-iul.pt

Selene G. Vicente

svicente@fpce.up.pt

${ }^{\dagger}$ Joint last authors.

Received: 04 July 2017 Accepted: 26 October 2017 Published: 09 November 2017

Citation:

Moreira HS, Costa AS, Castro SL, Lima CF and Vicente SG (2017) Assessing Executive Dysfunction in Neurodegenerative Disorders: A Critical Review of Brief

Neuropsychological Tools. Front. Aging Neurosci. 9:369. doi: 10.3389/fnagi.2017.00369

\section{Assessing Executive Dysfunction in Neurodegenerative Disorders: A Critical Review of Brief Neuropsychological Tools}

\author{
Helena S. Moreira ${ }^{1}$, Ana S. Costa ${ }^{2}$, São L. Castro ${ }^{1}$, César F. Lima ${ }^{1,3,4 * t}$ and \\ Selene G. Vicente ${ }^{1 * t}$ \\ ${ }^{1}$ Faculty of Psychology and Education Sciences, Centre for Psychology, University of Porto, Porto, Portugal, ${ }^{2}$ Neurology \\ Department, Hospital de Braga, Braga, Portugal, ${ }^{3}$ Institute of Cognitive Neuroscience, University College London, London, \\ United Kingdom, ${ }^{4}$ Instituto Universitário de Lisboa (ISCTE-IUL), Lisbon, Portugal
}

Executive function (EF) has been defined as a multifaceted construct that involves a variety of high-level cognitive abilities such as planning, working memory, mental flexibility, and inhibition. Being able to identify deficits in EF is important for the diagnosis and monitoring of several neurodegenerative disorders, and thus their assessment is a topic of much debate. In particular, there has been a growing interest in the development of neuropsychological screening tools that can potentially provide a reliable quick measure of EF. In this review, we critically discuss the four screening tools of EF currently available in the literature: Executive Interview-25 (EXIT 25), Frontal Assessment Battery (FAB), INECO Frontal Screening (IFS), and FRONTIER Executive Screen (FES). We first describe their features, and then evaluate their psychometric properties, the existing evidence on their neural correlates, and the empirical work that has been conducted in clinical populations. We conclude that the four screening tools generally present appropriate psychometric properties, and are sensitive to impairments in EF in several neurodegenerative conditions. However, more research will be needed mostly with respect to normative data and neural correlates, and to determine the extent to which these tools add specific information to the one provided by global cognition screening tests. More research directly comparing the available tools with each other will also be important to establish in which conditions each of them can be most useful.

Keywords: aging, cognitive impairment, executive functions, neuropsychological assessment, neurodegenerative disorders, neuropsychological screening, psychometric properties, review

\section{INTRODUCTION}

Aging is typically associated with a subtle decline in cognitive functioning, seen even in healthy individuals (Wild-Wall et al., 2011; Pertl et al., 2017). Crucially, though, aging is also a risk factor for neurodegenerative dementias, such as Alzheimer's and Parkinson's Diseases (Horton and Wedding, 2008). Cognitive screening tests are important to diagnose these conditions and to assess their evolution. Since they provide practical and cost-effective evaluations, using them can be extremely valuable for healthcare systems, that are often under pressure to reduce costs and operate under time constraints (Larner, 2013a). Guidelines for screening tests have been 
presented by the Committee on Research of the American Neuropsychiatric Association (Malloy et al., 1997): they should be brief ( $<15 \mathrm{~min}$ ), easy to administer, and present appropriate sensitivity, specificity, test-retest, and inter-rater validities. In primary care, clinicians typically rely on global cognition screening tools such as the Addenbrooke's Cognitive Examination (ACE; Mathuranath et al., 2000), Mini-Mental State Examination (MMSE; Folstein et al., 1975), or Montreal Cognitive Assessment (MoCA; Nasreddine et al., 2005). However, more specific screening instruments are also important (Cullen et al., 2007; Larner, 2013a), notably in diseases where deficits in specific cognitive domains are expected. Dysexecutive impairments, in particular, are an early feature of vascular (e.g., McGuiness et al., 2010) and neurodegenerative dementias (e.g., Baudic et al., 2006; Huey et al., 2009; Tartaglia et al., 2012). Screening tools for executive functions (EF) are thus central for evidence-based approaches in these conditions. In this review, we discuss the four currently available screening instruments for EF: Executive Interview (EXIT 25; Royall et al., 1992), Frontal Assessment Battery (FAB; Dubois et al., 2000), INECO Frontal Screening (IFS; Torralva et al., 2009), and FRONTIER Executive Screen (FES; Leslie et al., 2015).

\section{EXECUTIVE FUNCTIONS: DEFINITION AND NEUROANATOMICAL SUBSTRATES}

$\mathrm{EF}$ is an umbrella term for higher-order cognitive processes that coordinate cognitive, emotional, and motor activity during the execution of new and complex tasks (Jurado and Rosselli, 2007; Goldstein et al., 2014). Although, their pivotal role in cognition is established, a consensual definition is lacking (Goldstein et al., 2014). A theoretical distinction has been made between metacognitive and emotional EF. Metacognitive (Ardila, 2008; Funkiewiez et al., 2012; Otero and Barker, 2014) or cool EF (Miyake et al., 2000; Zelazo and Muller, 2002) include goal-directed, future-oriented skills such as planning, inhibition, flexibility, set-shifting, and working memory, typically assessed in relatively decontextualized, non-emotional testing conditions. Emotional (Ardila, 2008) or hot (Zelazo and Muller, 2002) EF, in turn, operate in contexts that involve emotion, motivation, or reward-based decision making. However, this distinction might not be straightforward and it has been suggested that metacognitive and emotional EF are closely related and interdependent (Panksepp, 2003; Peterson and Welsh, 2014). According to Panksepp (1998, 2003), they tend to go together in the most of human experiences, with affective/emotional processes providing intrinsic value for the cognitive and behavioral systems (see also Pessoa, 2009).

Neuroimaging studies with healthy adults (e.g., Collette et al., 2006; Burzynska et al., 2012) and brain-damaged patients (e.g., Robinson et al., 2014) indicate that EF are supported by distributed networks including frontal and posterior (mainly parietal) cortical and subcortical regions. For instance, studies using structural techniques found positive correlations between prefrontal cortex (PFC) volume and performance on tasks of EF such as the Wisconsin Card Sorting Test (WCST;
Gunning-Dixon and Raz, 2003; Burzynska et al., 2012). Evidence from functional studies (fMRI) implicates the dorsolateral PFC (dlPFC) and anterior cingulate areas in the performance of metacognitive tasks such as the Tower of Hanoi (Unterrainer et al., 2004), digit span (Yoon et al., 2007) and WCST (Wilmsmeier et al., 2010). On the other hand, fMRI studies with patients with frontotemporal degeneration implicate the ventromedial $\mathrm{PFC}$ in the mechanisms of emotional/social decision (Grossman et al., 2010; for a review of the PFC involvement in social EF, see Bicks et al., 2015).

Deficits in EF are a common symptom of traumatic (Caeyenberghs et al., 2014), vascular (McGuiness et al., 2010), neuropsychiatric (Reichenberg et al., 2009; Fiorentino et al., 2013; Baez et al., 2014; Caixeta et al., 2017), and neurodegenerative conditions. Concerning neurodegenerative conditions, executive dysfunction is a core symptom of behavioral-variant frontotemporal dementia (bvFTD; Hodges and Miller, 2001; Slachevsky et al., 2004; Fiorentino et al., 2013), and it is also frequent in Parkinson's (Lima et al., 2008; Dirnberger and Jahanshahi, 2013) and Huntington's diseases (You et al., 2014). Metacognitive EF, namely planning, working memory and fluency, seem to be the most affected ones in Parkinson's and Huntington's diseases (Elliott, 2006; Leh et al., 2010; You et al., 2014). On the other hand, bvFTD causes both metacognitive (Huey et al., 2009) and motivational/emotional impairments (Eslinger et al., 2012). Early stage AD patients also show executive dysfunction (e.g., Amiéva et al., 2004), possibly before global cognition deficits are detectable using screening measures such as MMSE (Sgaramella et al., 2001; Stokholm et al., 2006; Clark et al., 2012). Importantly, in these patients, the magnitude of EF dysfunction predicts worse performance in daily living activities, greater need of care, and higher frequency of neuropsychiatric symptoms (Tekin et al., 2001; Swanberg et al., 2004; Stokholm et al., 2006).

Efforts have been made to develop tools to assess executive dysfunction. Although, detailed tests and comprehensive batteries are available (e.g., Behavioral Assessment of Dysexecutive Syndrome, Wilson et al., 1996), the interest in screening tools is relatively more recent. For example, they are not yet discussed in widely used neuropsychological assessment handbooks (e.g., Strauss et al., 2006; Lezak et al., 2012). As compared to comprehensive batteries, screening tools can provide an easier, reliable, and quicker measure of EF, useful in initial assessments, or when the available time and resources are limited.

\section{SCREENING TOOLS OF EXECUTIVE FUNCTIONS}

Four executive screening tools have been devised so far: EXIT 25, FAB, IFS, and FES (see Table 1 for details).

EXIT25 (Royall et al., 1992) was the first screening tool designed to assess EF, including working memory, verbal and visual fluency, inhibitory control, motor programming, and imitation behavior. It consists of 25 items and takes around $15 \mathrm{~min}$ to administer. The scores range from 0 to 50 , with 

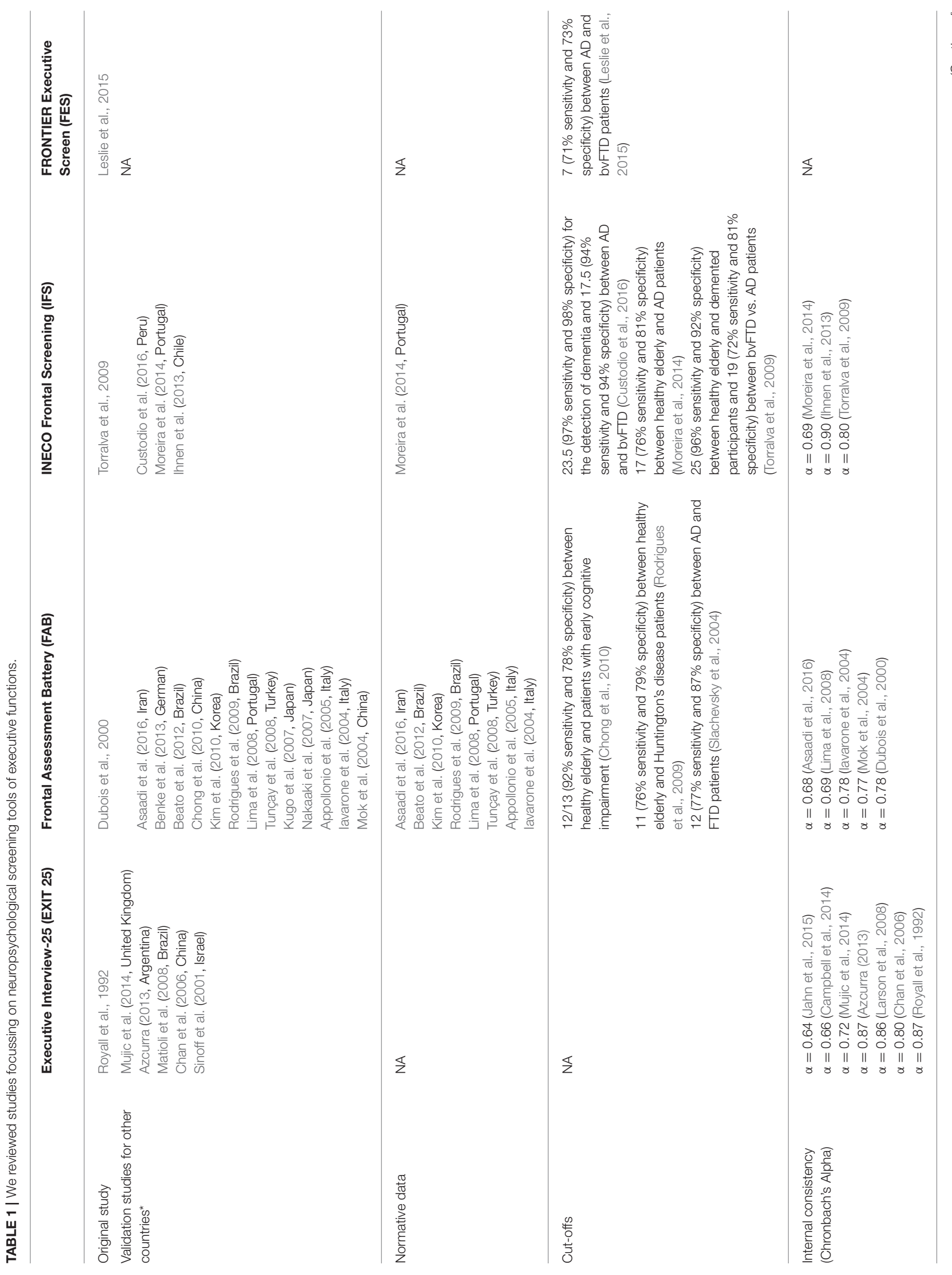


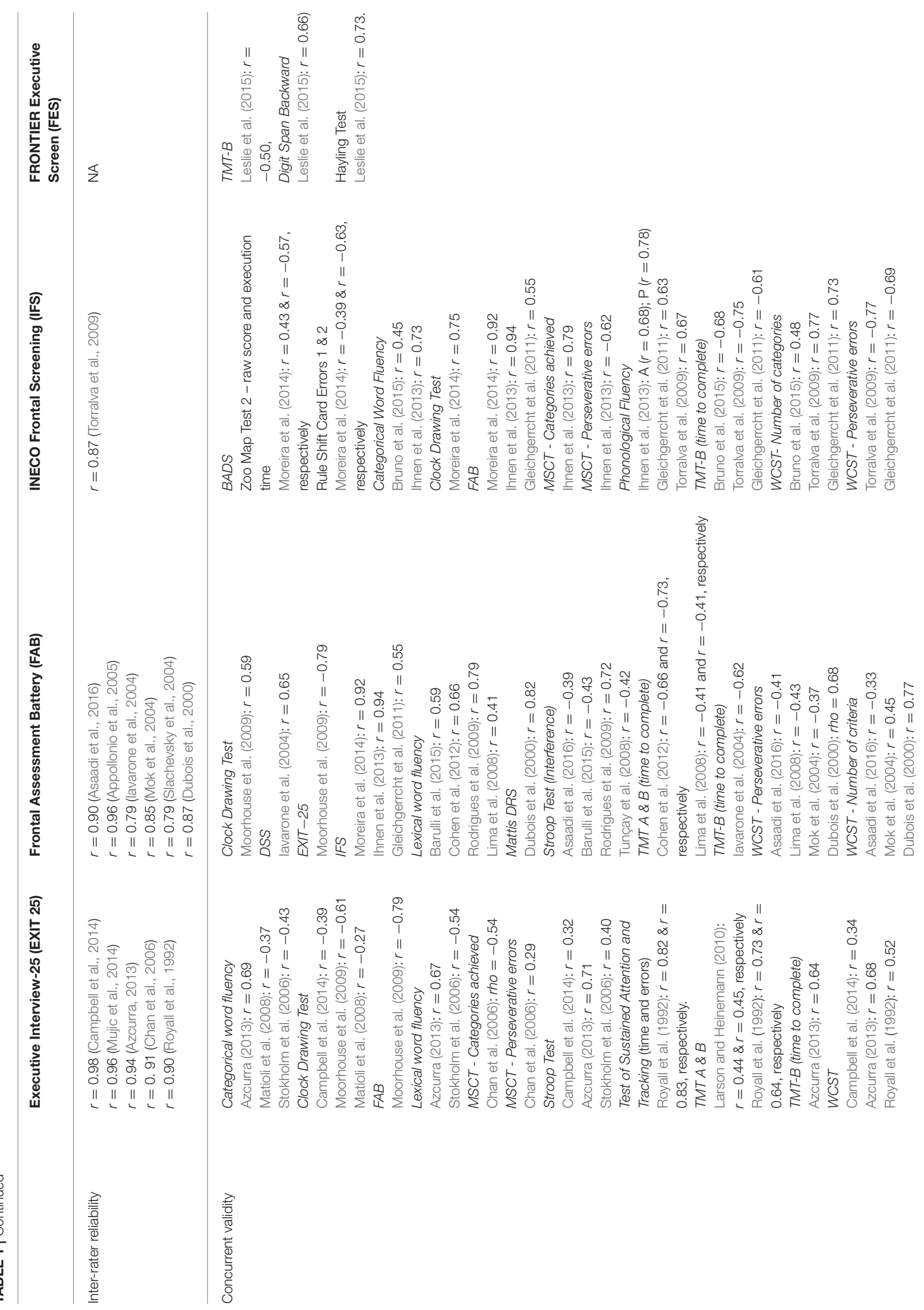




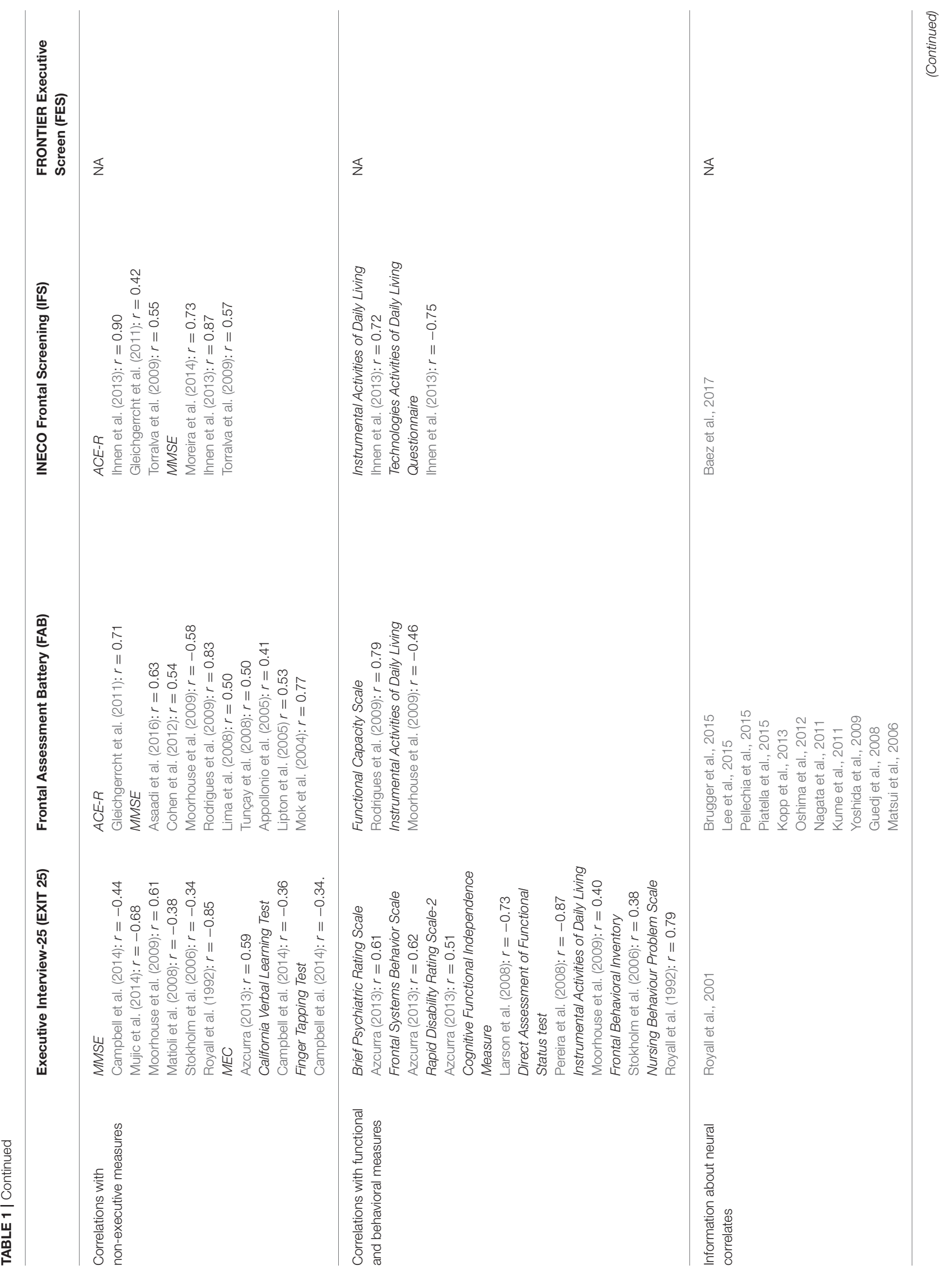




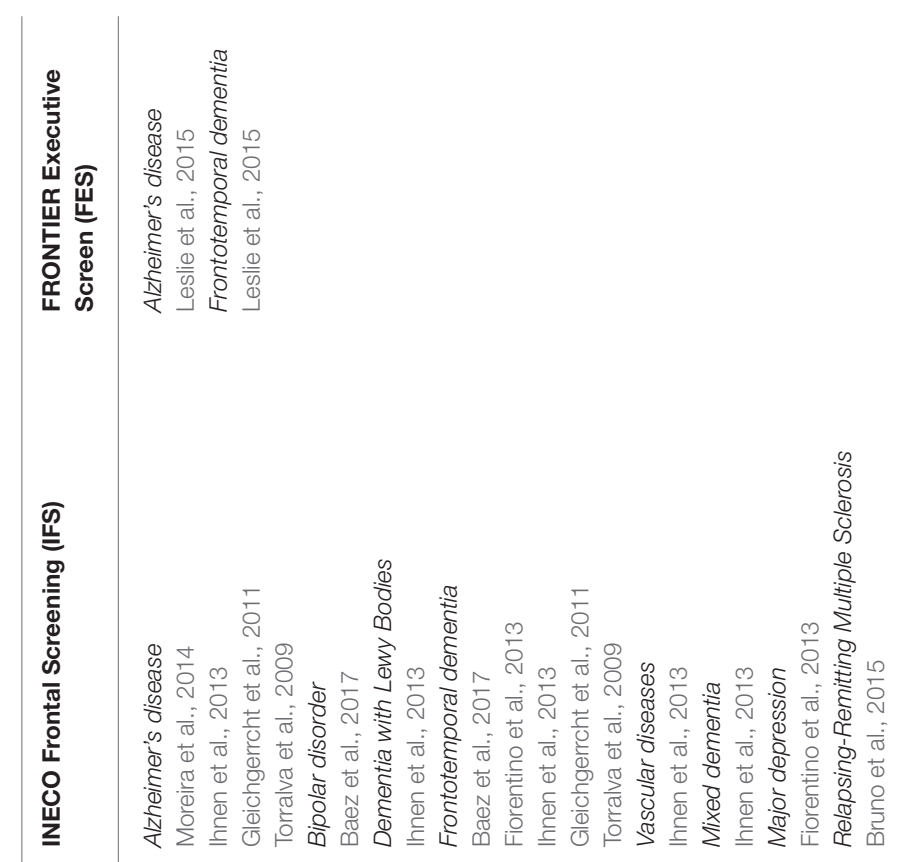

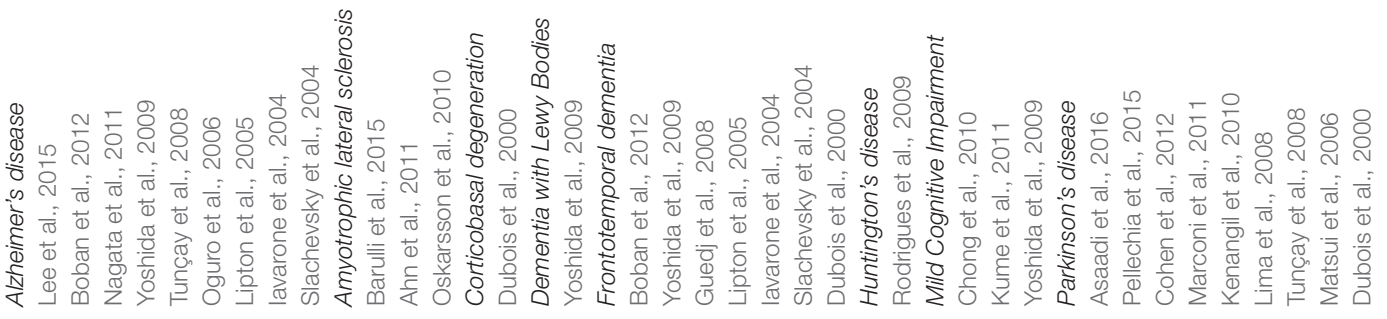

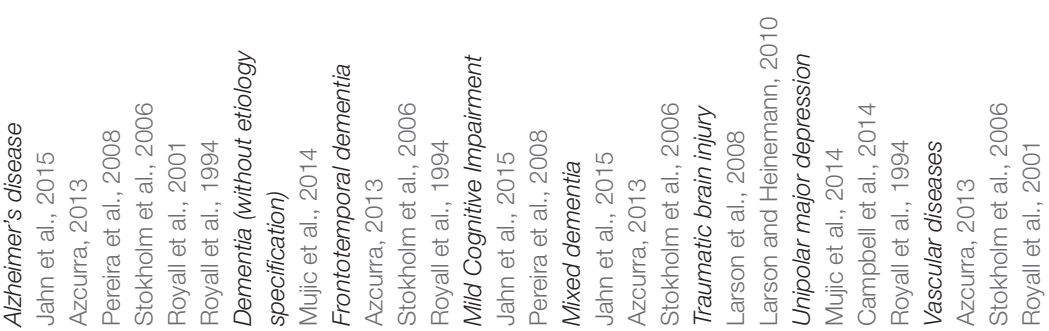




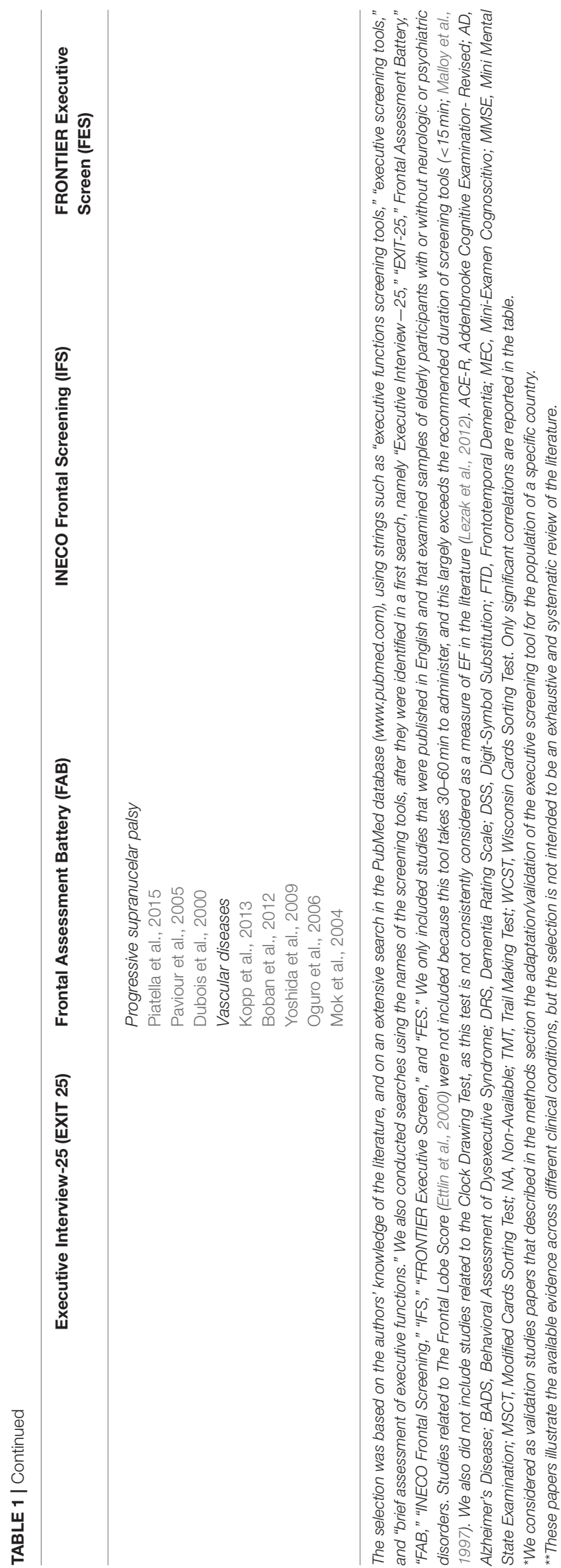

higher values indicating worse performance. The validation study compared EXIT 25 scores across elderly groups with different levels of functional dependency. Contrary to the MMSE, EXIT 25 discriminated between groups, and presented good psychometric properties, namely good internal consistency, inter-rater reliability, and strong correlations with standard EF measures, including the Trail Making Test B (TMT-B), the Test of Sustained Attention, and the WCST (Ray et al., 1992; Royall et al., 1992). Associations between higher EXIT 25 scores and disruptive behaviors (Ray et al., 1992), functional decline (Royall et al., 2004; Pereira et al., 2008), and probability of dementia (Stokholm et al., 2006) were also found. Left anterior frontal lobes lesions related to worse EXIT 25 performance in studies with vascular and $\mathrm{AD}$ patients, even when controlling for age, dementia type and severity (Royall et al., 2001). Further studies also confirmed EXIT 25's ability to detect executive dysfunction in neurodegenerative (e.g., AD, FTD; Stokholm et al., 2006; Azcurra, 2013) and non-degenerative (e.g., traumatic brain injury; Larson et al., 2008) conditions. However, it failed to differentiate between patients with probable AD with and without major depression, vascular dementia without cortical features, and schizophrenia (Royall et al., 1994). Another limitation of EXIT 25 is its significant correlations with non-EF measures such as the MMSE (Royall et al., 1992; Matioli et al., 2008; Campbell et al., 2014), the California Verbal Learning Test and the Finger Taping Test (Campbell et al., 2014). This could indicate poor specificity (Dubois et al., 2000). Campbell et al. (2014) argued that although poor scores on EXIT 25 indicate cognitive deficits with an executive component, it is not a specific measure of $\mathrm{EF}$ alone. There are validation studies for countries like the United Kingdom (Mujic et al., 2014), Argentina (Azcurra, 2013), Brazil (Matioli et al., 2008), China (Chan et al., 2006), and Israel (Sinoff et al., 2001), but normative data and cut-offs were not provided. Shorter versions have been presented. The Quick EXIT (Larson and Heinemann, 2010) incudes 14-items and shows good internal consistency (Cronbach's alpha $=0.88$ ) and moderate correlations with other measures of EF such as TMT (Campbell et al., 2014). The EXIT 8 (Jahn et al., 2015) is an 8-item version that shows good internal consistency (Cronbach's alpha $=$ 0.74 ), high correlation with the full EXIT 25 , and good ability to discriminate controls from patients (Area Under Curve-AUC $=0.81$ for Mild Cognitive Impairment, and AUC $=0.92$ for dementia). EXIT 8 remains a significant predictor of other EF measures after controlling for MMSE scores, which suggests that it might be a robust measure. Despite the good indicators, studies considering other clinical populations are warranted.

To derive a more specific tool than EXIT 25, Dubois et al. (2000) developed the FAB, which became the most widely used screening tool for EF. It takes around $10 \mathrm{~min}$ to administer, and consists of six subtests that assess conceptualization, mental flexibility, motor programming, sensitivity to interference, inhibitory control, and environmental autonomy. Higher values (minimum of 0 and maximum of 18) indicate better EF. The FAB presented good inter-rater reliability and internal consistency, strong positive correlations with the WCST, and a good discriminative ability between controls and patients with Parkinson's disease, corticobasal degeneration, 
FTD, and progressive supranuclear palsy (Dubois et al., 2000). Its psychometric properties were further inspected: strong correlations were found with measures such as TMT, verbal fluency (Lima et al., 2008; Rodrigues et al., 2009) and Stroop Test (Rodrigues et al., 2009), as well as high inter-rater reliability (Appollonio et al., 2005), and high accuracy in differentiating controls from patients with FTD (Slachevsky et al., 2004; Lipton et al., 2005), Parkinson's disease (PD; Lima et al., 2008), AD (Slachevsky et al., 2004; Guedj et al., 2008), Huntington's disease (Rodrigues et al., 2009), and amyotrophic lateral sclerosis (Barulli et al., 2015). Associations were found between FAB performance and regional cerebral glucose metabolism in dlPFC and middle frontal gyri areas in AD patients (Oshima et al., 2012; Lee et al., 2015), with dorsolateral prefrontal cortex and parietal lobe areas in PD patients (Brugger et al., 2015), and with perfusion in the dlPFC, medial premotor cortex and anterior cingulate cortex in bvFTD patients (Guedj et al., 2008; for a review of FAB neural correlates see Hurtado-Pomares et al., 2017). Different versions of this tool and normative data are available, for example, in Iranian (Asaadi et al., 2016), German (Benke et al., 2013), Brazilian Portuguese (Beato et al., 2012), Korean (Kim et al., 2010), European Portuguese (Lima et al., 2008), Turkish (Tunçay et al., 2008), Japanese (Kugo et al., 2007), Italian (Iavarone et al., 2004; Appollonio et al., 2005), and Chinese (Mok et al., 2004; Chong et al., 2010). A cut-off of 12 distinguished between FTD and $\mathrm{AD}$ patients with good sensitivity and specificity (Iavarone et al., 2004; Slachevsky et al., 2004). For patients with Huntington's disease, a cut-off of 10/11 achieved the best sensitivity and specificity (Rodrigues et al., 2009). In comparisons with EXIT 25 , it was noticed that despite their similarities, FAB was briefer and easier to administer in a memory clinic setting (Moorhouse et al., 2009). Its contribution for differential diagnosis remains non-consensual, however. FAB differentiated patients with $\mathrm{AD}$ and vascular dementia (Oguro et al., 2006). Concerning byFTD and $\mathrm{AD}$ patients, although bvFTD presented lower scores in some studies (Iavarone et al., 2004; Slachevsky et al., 2004; Nakaaki et al., 2007), in other studies differences were not significant (Castiglioni et al., 2006; Gleichgerrcht et al., 2011). Additionally, some of its subtests have been shown to have poor sensitivity (e.g., Prehension Behaviour and Letter Fluency; Lima et al., 2008; Moreira et al., 2014). Age (Iavarone et al., 2004; Appollonio et al., 2005; Lima et al., 2008) and education (Iavarone et al., 2004; Appollonio et al., 2005; Rodrigues et al., 2009) should be considered when interpreting FAB scores, since they are predictors of performance, with advanced age and less years of education predicting lower scores. FAB correlates with MMSE in many studies (e.g., Lima et al., 2008; Moorhouse et al., 2009; Rodrigues et al., 2009), suggesting that, like EXIT 25, this measure relates to other cognitive domains.

More recently, Torralva et al. (2009) developed the Institute of Cognitive Neurology (INECO) Frontal Screening (IFS). The IFS takes around $10 \mathrm{~min}$ to administer, includes eight subtests that cover three executive domains (response inhibition and set shifting, abstraction, and working memory), and assess processes such as motor programming, sensitivity to interference, inhibitory control, verbal inhibitory control, abstraction, and working memory. Three subtests (Motor series, Conflicting instructions, and Go-no-go) were taken from FAB, whereas the remaining ones (Backward digit span; Months of the year backward; Modified Corsi block, Proverb interpretation and Modified Hayling test) were selected to optimize sensitivity. The total score ranges from 0 to 30 , with higher scores indicating better performance. Psychometric properties were reported: good internal consistency and concurrent validity, as shown by strong correlations with standard measures of EF such as the WCST, TMT-B (Torralva et al., 2009; Gleichgerrcht et al., 2011) and Lexical and Semantic Fluency (Torralva et al., 2009; Ihnen et al., 2013). Additionally, associations with functional measures have been found, such as the Activities of Daily Living Scale (Ihnen et al., 2013). The IFS discriminate between healthy controls and patients with bvFTD (Torralva et al., 2009; Gleichgerrcht et al., 2011; Fiorentino et al., 2013; Custodio et al., 2016), AD (Torralva et al., 2009; Gleichgerrcht et al., 2011; Moreira et al., 2014; Custodio et al., 2016), relapsing-remitting multiple sclerosis (Bruno et al., 2015), bipolar disorder and ADHD (Baez et al., 2014), as well as between clinical conditions, with bvFTD patients scoring lower than those with major depression (Fiorentino et al., 2013) and AD (Torralva et al., 2009; Custodio et al., 2016). Cutoffs have been presented throughout the studies, with overall values of sensitivity and specificity above 70\%: 23.5 (Custodio et al., 2016) and 25 (Torralva et al., 2009) for the detection of dementia, and 17.5 (Custodio et al., 2016) and 19 (Torralva et al., 2009) for the discrimination between bvFTD and AD patients. In a sample with lower education, Moreira et al. (2014) showed that an optimal cut-off of 17 discriminated between healthy controls from $\mathrm{AD}$ patients. Only one study explored the neural correlates of IFS, finding that total scores were associated with atrophy in the amygdala, the hippocampus, the parahippocampal gyrus, the fusiform gyrus, and the orbitofrontal cortex in bvFTD patients (Baez et al., 2017). Comparisons between IFS and FAB were undertaken, and these have shown that IFS is more sensitive and specific in differentiating bvFTD from AD (Gleichgerrcht et al., 2011; Custodio et al., 2016), and it also correlates more strongly with standard executive tasks (e.g., TMT-B, WCST, Gleichgerrcht et al., 2011). Nonetheless, the advantage of IFS over FAB remains to be established: in a study with $\mathrm{AD}$ patients, they showed similar diagnostic accuracy ( 0.88 and 0.87 , respectively) and similar correlations with other measures of EF (Moreira et al., 2014). IFS scores also correlate with MMSE scores (Torralva et al., 2009; Ihnen et al., 2013; Moreira et al., 2014) and are influenced by age (Moreira et al., 2014) and education (Ihnen et al., 2013; Moreira et al., 2014), reinforcing the need of normative data to take these variables into account. To our knowledge, though, normative data are only available for the Portuguese IFS (Moreira et al., 2014).

Finally, Leslie et al. (2015) developed the FRONTIER Executive Screen (FES), a tool that combines tasks believed to differentiate bvFTD from AD, namely verbal fluency, inhibition, and working memory. The scores range from 0 to 15 , with higher values indicating better performance. The FES showed good discriminant accuracy between controls and patients, and between $\mathrm{AD}$ and bvFTD groups (a cut-off of 7 reached good sensitivity and specificity). Strong correlations with standard EF measures were found (TMT-B, Digit Span Backward, and 
the Hayling Test). However, compared with the other screening tools, FES covers less executive domains, and this could reduce its sensitivity. Additionally, the highly specific FES goal-to differentiate patients with bvFTD and AD—, along with the absence of normative data, may limit its clinical usefulness. Studies focused on the influence of sociodemographic variables in FES performance and on its neural correlates remain to be conducted as well.

\section{DISCUSSION AND FUTURE DIRECTIONS}

Deficits in EF are a symptom of several disorders and screening tools are a promising method for their reliable and fast assessment. We have discussed the four screening tools of EF currently available. A common feature to the discussed tools is the emphasis on metacognitive EF. Thus, for patients with deficits in affective/social components (e.g., bvFTD; Rahman et al., 1999; Eslinger et al., 2012), they might provide more limited information. The Social Cognition and Emotional Assessment (SEA; Funkiewiez et al., 2012) and mini SEA (Bertoux et al., 2012) could be an option in these cases, though they take longer than $30 \mathrm{~min}$ to be completed.

Special attention has been given to the psychometric properties of screening tools of EF, as these are critical to determine their clinical utility (Cullen et al., 2007; Larner, 2013a). All the discussed tools show good psychometric properties according to the available guidelines (Malloy et al., 1997). Apart from the FES, that still lacks this analysis, all of them show good internal consistency and inter-rater reliability. The IFS and FES show similar accuracy in detecting executive impairments in bvFTD as compared to $\mathrm{AD}$. In turn, FES seems to be more prone to wrong classifications, as indicated by its lower specificity. Correlations with standard executive measures were consistently found. However, all the executive screening tools also presented correlations with measures of global cognition like the MMSE. This has been pointed out as a limitation, i.e., a sign of low specificity. Nonetheless, considering the multifaceted nature of $\mathrm{EF}$, it is reasonable to expect that they influence performance in global cognitive measures, as these include executive components themselves. More studies will be needed to establish whether screening tools of EF provide information that is useful over and above that provided by global cognitive measures.

The availability of normative data is key for clinical practice: conclusions about deficits are more reliable if performance is compared against population data matched for age and education. Unfortunately, insufficient attention has been given to this. Only FAB and IFS presented normative studies, and only in some of the countries where they have been validated. This limits the utility of these tools and deserves more attention in future work.

Another point that deserves more attention in future research is the relative usefulness of executive screening tools in the different stages of neurodegenerative diseases. Progression generally occurs toward generalized deficits (Horton and Wedding, 2008), and this makes the interpretation (and diagnostic value) of domain-specific assessments more challenging. Executive screening tools could be useful for differential diagnosis in earlier stages of the disease (when combined with other measures), while their contribution in later stages could be more related to the description of the neurocognitive phenotype, i.e., the pattern of relatively preserved and impaired functions.

The relationship between screening tools and brain structure and function remains poorly explored as well. This is crucial to examine whether these tools recruit the same systems that have been identified in experimental cognitive neuroscience research. For EXIT 25 and FAB, there is some evidence of associations with prefrontal structures. However, this remains poorly explored for the IFS and unknown for the FES.

Apart from FES, which is briefer, the remaining executive screening tools are relatively similar concerning structure, time of application, covered domains, and psychometric properties. More comparative research will be critical, across different clinical groups, to establish in which conditions each of the available tools is most useful. Larner (2013b), for example, compared some screening measures of global cognition, providing conclusions that are highly valuable for clinicians. Some attempts to compare FAB, EXIT 25, and IFS in AD and bvFTD patients have been made, but conclusive evidence is still missing.

\section{AUTHOR CONTRIBUTIONS}

HM, AC, CL, and SV contributed to the conception and design of the work. HM prepared the first draft of the work, and AC, SC, CL, and SV revised it critically for important intellectual content. All authors approved the final version of the manuscript.

\section{FUNDING}

This work was partially supported by grants from the Portuguese Foundation for Science and Technology (FCT) and the COMPETE 2020 program (CPUP UID/PSI/00050/2013, POCI01-0145-FEDER-0072, and NORTE-01-0145-FEDER-00026). HM is supported by a grant from FCT (SFRH/BD/105201/2014). CL is supported by an FCT Investigator Grant (IF/00172/2015).

\section{REFERENCES}

Ahn, S., Kim, S., Kim, J., Kim, S., Kim, S., Sung, J., et al. (2011). Frontal assessment battery to evaluate frontal lobe dysfunction in ALS patients. Can. J. Neurol. Sci. 38, 242-246. doi: 10.1017/S0317167100011409

Amiéva, H., Lafont, S., Rouch-Leroyer, I., Rainville, C., Dartigues, J. F., Orgogozo, J. M., et al. (2004). Evidencing inhibitory deficits in Alzheimer Disease

through interference effects and shifting disabilities in Stroop Test. Arch. Clin. Neuropsychol. 19, 791-803. doi: 10.1016/j.acn.2003.09.006

Appollonio, I., Leone, M., Isella, V., Piamarta, F., Consoli, T., Villa, M. L., et al. (2005). The frontal assessment battery (FAB): normative values in an Italian population sample. Neurol. Sci. 26, 108-116. doi: 10.1007/s10072-005-0443-4

Ardila, A. (2008). On the evolutionary origins of executive functions. Brain Cogn. 68, 92-99. doi: 10.1016/j.bandc.2008.03.003 
Asaadi, S., Ashrafi, F., Omidbeigi, M., Nasiri, Z., Pakdaman, H., and AminiHarandi, A. (2016). Persian version of frontal assessment battery: correlations with formal measures of executive functioning and providing normative data for Persian population. Iran J. Neurol. 15, 16-22.

Azcurra, S. (2013). Spanish translation and validation of an Executive Battery 25 (EB25) and its shortened version (ABE12) for executive dysfunction screening in dementia. Neurologia 28, 457-476. doi: 10.1016/j.nrl.2010.12.020

Baez, S., Ibanez, A., Gleichgerrcht, E., Perez, A., Roca, M., Manes, F., et al. (2014). The utility of IFS (INECO Frontal Screening) for the detection of executive dysfunction in adults with bipolar disorder and ADHD. Psychiatry Res. 216, 269-276. doi: 10.1016/j.psychres.2014.01.020

Baez, S., Pinasco, C., Roca, M., Ferrari, J., Couto, B., García-Cordero, I., et al. (2017). Brain structural correlates of executive and social cognition profiles in behavioral variant frontotemporal dementia and elderly bipolar disorder. Neuropsychologia. doi: 10.1016/j.neuropsychologia.2017.02.012. [Epub ahead of print].

Barulli, M. R., Fontana, A., Panza, F., Copetii, M., Bruno, S., Tursi, M., et al. (2015). Frontal assessment battery for detecting executive dysfunction in amyotrophic lateral sclerosis without dementia: a retrospective observational study. $B M J$ Open 5:e007069. doi: 10.1136/bmjopen-2014-007069

Baudic, S., Barba, G. D., Thibaudet, M. C., Smagghe, A., Remy, P., and Traykov, L. (2006). Executive function deficits in early Alzheimer's disease and their relations with episodic memory. Arch. Clin. Neuropsychol. 21, 15-21. doi: 10.1016/j.acn.2005.07.002

Beato, R., Amaral-Carvalho, V., Guimarães, H. C., Tumas, V., Souza, C. P., Oliveira, G. N., et al. (2012). Frontal assessment battery in a Brazilian sample of healthy controls: normative data. Arq. Neuropsiquiatr. 70, 278-280. doi: 10.1590/S0004-282X2012005000009

Benke, T., Karner, E., and Delazer, M. (2013). FAB-D: German version of the frontal assessment battery. J. Neurol. 260, 2066-2072. doi: 10.1007/s00415-013-6929-8

Bertoux, M., Delavest, M., de Souza, L. C., Funkiewiez, A., Lépine, J.-P., Fossati, P., et al. (2012). Social cognition and emotional assessment differentiates frontotemporal dementia from depression. J. Neurol. Neurosurg. Psychiatry 83, 411-416. doi: 10.1136/jnnp-2011-301849

Bicks, L. K., Koike, H., Akbarian, S., and Morishita, H. (2015). Prefrontal cortex and social cognition in mouse and man. Front. Psychol. 6:1805. doi: 10.3389/fpsyg.2015.01805

Boban, M., Malojcić, B., Mimica, N., Vuković, S., and Zrilic, I. (2012). The frontal assessment battery in the differential diagnosis of dementia. J. Geriatr. Psychiatry Neurol. 25, 201-207. doi: 10.1177/0891988712464821

Brugger, F., Abela, E., Hägele-Link, S., Bohlhalter, S., Galovic, M., and Kägi, G. (2015). Do executive dysfunction and freezing of gait in Parkinson's disease share the same neuroanatomical correlates? J. Neurol. Sci. 356, 184-187. doi: 10.1016/j.jns.2015.06.046

Bruno, D., Torralva, T., Marenco, V., and Roca, M. (2015). Utilization of the INECO Frontal Screening (IFS) in the detection of executive dysfunction in patients with relapsing-remitting multiple sclerosis (RRMS). Neurol. Sci. 36, 2035-2041. doi: 10.1007/s10072-015-2299-6

Burzynska, A. Z., Nagel, I. E., Preuschhof, C., Gluth, S., Bäckman, L., Li, S. C., Lindenberger, U., et al. (2012). Cortical thickness is linked to executive functioning in adulthood and aging. Hum. Brain Mapp. 33, 1607-1620. doi: $10.1002 / \mathrm{hbm} .21311$

Caeyenberghs, K., Leemans, A., Leunissen, I., Gooijers, J., Michiels, K., Sunaert, S., et al. (2014). Altered structural networks and executive deficits in traumatic brain injury patients. Brain Struct. Funct. 219, 193-209. doi: 10.1007/s00429-012-0494-2

Caixeta, L., Soares, V. L. D., Vieira, R. T., Soares, C. D., Caixeta, V., Ferreira, S. B., et al. (2017). Executive function is selectively impaired in old age bipolar depression. Front. Psychol. 8:194. doi: 10.3389/fpsyg.2017.00194

Campbell, G. B., Whyte, E. M., Sereika, M., Dew, M. A., Reynolds, C. F., and Butters, M. A. (2014). Reliability and validity of the executive interview (EXIT) and Quick EXIT among community dwelling older adults. Am. J. Geriatr. Psychiatry 22, 1444-1451. doi: 10.1016/j.jagp.2013.08.009

Castiglioni, S., Pelati, O., Zuffi, M., Somalvico, F., Marino, L., Tentorio, T., et al. (2006). The frontal assessment battery does not differentiate frontotemporal dementia from Alzheimer's Disease. Dement. Geriatr. Cogn. Disord. 22, 125-131. doi: 10.1159/000093665
Chan, S. M. S., Chiu, F. K. H., and Lam, C. W., L (2006). Correlational study of the Chinese version of the executive interview (C-EXIT25) to other cognitive measures in a psychogeriatric population in Hong Kong Chinese. Int. J. Geriatr. Psychiatry 21, 535-541. doi: 10.1002/gps.1521

Chong, M. S., Lim, W. S., Chan, S. P., Feng, L., Niti, M., Yap, P., et al. (2010). Diagnostic performance of the Chinese frontal assessment battery in early cognitive impairment in an Asian population. Dement. Geriatr. Cogn. Disord. 30, 525-532. doi: 10.1159/000321665

Clark, L., Schiehser, D. M., Weissberger, G. H., Salmon, D. P., Delis, D. C., and Bondi, M. W. (2012). Specific measures of executive function predict cognitive decline in older adults. J. Int. Neuropsychol. Soc. 18, 1118-1127. doi: 10.1017/S1355617711001524

Cohen, O. S., Vakil, E., Tanne, D., Molshatzki, N., Nitsan, Z., and Hassin-Baer, S. (2012). The frontal assessment battery as a tool for evaluation of frontal lobe dysfunction in patients with Parkinson Disease. J. Geriatr. Psychiatry Neurol. 25, 71-77. doi: 10.1177/0891988712445087

Collette, F., Hogge, M., Salmon, E., and Van der Linden, M. (2006). Exploration of the neural substracts of executive functioning by functional neuroimaging. Neuroscience 139, 209-211. doi: 10.1016/j.neuroscience.2005. 05.035

Cullen, B., O’Neill, B., Evans, J. J., Coen, R. F., and Lawlor, B. (2007). A review of screening tests for cognitive impairment. J. Neurol. Neurosurg. Psychiatry 78, 790-799. doi: 10.1136/jnnp.2006.095414

Custodio, N., Herrera-Perez, E., Lira, D., Roca, M., Manes, F., Baez, S., et al. (2016). Evaluation of the INECO frontal screening and the frontal assessment battery in Peruvian patients with Alzheimer's disease and behavioral variant frontotemporal dementia. eNeurologicalSci 5, 25-29. doi: 10.1016/j.ensci.2016.11.001

Dirnberger, G., and Jahanshahi, M. (2013). Executive dysfunction in Parkinson's disease: a review. J. Neuropsychol. 7, 193-224. doi: 10.1111/jnp.12028

Dubois, B., Slachevsky, A., Litvan, I., and Pillon, B. (2000). The FAB: a frontal assessent battery at bedside. Neurology 55, 1621-1626. doi: 10.1212/WNL.55.11.1621

Elliott, R. (2006). Executive functions and their disorders. Br. Med. Bull. 65, 45-50. doi: $10.1093 / \mathrm{bmb} / 65.1 .49$

Eslinger, P. J., Moore, P., Antani, S., Anderson, C., and Grossman, M. (2012). Apathy in frontotemporal dementia: behavioral and neuroimaging correlates. Behav. Neurol. 25, 127-136. doi: 10.1155/2012/286427

Ettlin, T. M., Kischhka, U., Beckson, M., Gaggioti, M., and Rauchfleisch, U. (2000). The Frontal Lobe Score: part I: construction of a mental status of frontal systems. Clin. Rehabil. 14, 260-271. doi: 10.1191/0269215006696 35136

Fiorentino, N., Gleichgerrcht, E., Roca, M., Cetkovich, M., Manes, F., and Torralva, T. (2013). The INECO Frontal Screening tool diferentiates behavioral variant-frontotemporal dementia (by-FTD) for major depression. Dement. Neuropsychol. 7, 33-39. doi: 10.1590/S1980-57642013DN701 00006

Folstein, M. F., Folstein, S. E., and McHugh, P. R. (1975). "Mini-mental state". A practical method for grading the cognitive state of patients for the clinician. J. Psychiatr. Res. 12, 189-198. doi: 10.1016/0022-3956(75) 90026-6

Funkiewiez, A., Bertoux, M., Souza, L. C., Lévy, R., and Dubois, B. (2012). The SEA (Social and Cognition and Emotional Assessment): a clinical neuropsychological tool for early diagnosis of frontal variant of frontotemporal lobar degeneration. Neuropsychology 26, 81-90. doi: 10.1037/a0025318

Gleichgerrcht, E., Roca, M., Manes, F., and Torralva, T. (2011). Comparing the clinical usefulness of the Institute of Cognitive Neurology (INECO) Frontal Screening (IFS) and the Frontal Assessment Battery (FAB) in frontotemporal dementia. J. Clin. Exp. Neuropsychol. 33, 997-1004. doi: 10.1080/13803395.2011.589375

Goldstein, S., Naglieri, J. A., Princiotta, D., and Otero, T. M. (2014). "Introduction: a history of executive functioning," in Handbook of Executive Functioning, eds S. Goldstein and J. A. Naglieri (New York, NY: Springer), 24-44.

Grossman, M., Eslinger, P. J., Troiani, V., Anderson, C., Avants, B., Gee, J. C., et al. (2010). The role of ventral medial prefrontal cortex in social decisions: converging evidence from fMRI and Frontotemporal Lobar Degeneration. Neuropsychologia, 48, 3505-3512. doi: 10.1016/j.neuropsychologia.2010.07.036 
Guedj, E., Allali, G., Goetz, C., Le Ber, I., Volteau, M., Lacomblez, L., et al. (2008). Frontal assessment battery is a marker of dorsolateral and medial frontal functions: a SPECT study in frontotemporal dementia. J. Neurol. Sci. 272, 84-87. doi: 10.1016/j.jns.2008.06.035

Gunning-Dixon, F. M., and Raz, N. (2003). Neuroanatomical correlates of selected executive functions in middle-aged and older adults: a prospective MRI study. Neuropsychologia 41, 1929-1941. doi: 10.1016/S0028-3932(03)00129-5

Hodges, J. R., and Miller, B. (2001). "Frontotemporal dementia (Pick's disease)," in Early Onset Dementia: A Multidisciplinary Approach, ed J. R. Hodges (Cambrige: Oxford University Press), 284-303.

Horton, A. M., and Wedding, D. (eds) (2008). The Neuropsychology, 3rd Edn. New York, NY: Springer Publishing Company.

Huey, E. D., Goveia, E. N., Paviol, S., Pardini, M., Krueger, F., Zamboni, G., et al. (2009). Executive dysfunction in frontotemporal dementia and corticobasal syndrome. Neurology 72, 453-459. doi: 10.1212/01.wnl.0000341781.39164.26

Hurtado-Pomares, M., Carmen Terol-Cantero, M., Sánchez-Pérez, A., PeralGómez, P., Valera-Gran, D., and Navarrete-Muñoz, E. M. (2017). The frontal assessment battery in clinical practice: a systematic review. Int. J. Geriatr. Psychiatry. doi: 10.1002/gps.4751. [Epub ahead of print].

Iavarone, A., Ronga, B., Pellegrino, L., Loré, E., Vitaliano, S., Galeone, F., et al. (2004). The Frontal Assessment Battery (FAB): normative data from an Italian sample and performances of patientes with Alzheimer's disease and frontotemporal dementia. Funct. Neurol. 19, 191-195.

Ihnen, J., Antivilo, A., Mu-oz-Neira, C., and Slachevsky, A. (2013). Chilean version of the INECO Frontal Screening (IFS-Ch). Dement. Neuropsychol. 7, 40-47. doi: 10.1590/S1980-57642013DN70100007

Jahn, D. R., Dressel, J. A., Gavett, B. E., and O'Bruant, S. E. (2015). An item response theory analysis of the executive interview and development of the EXIT 8: a project FRONTIER Study. J. Clin. Exp. Neuropsychol. 37, 229-242. doi: $10.1080 / 13803395.2014 .1002757$

Jurado, M. B., and Rosselli, M. (2007). The elusive nature of executive functions: a review of our current understanding. Neuropsychol. Rev. 17, 713-725. doi: 10.1007/s11065-007-9040-z

Kenangil, G., Orken, D. N., Ur, E., and Forta, H. (2010). Frontal assessment battery in patients With Parkinson Disease in a Turkish Population. Cogn. Behav. Neurol. 23, 26-28. doi: 10.1097/WNN.0b013e3181c5e2b0

Kim, H., Huh, Y., Choe, J., Jeong, J. W., Park, J. H., Lee, S. B., et al. (2010). Korean version of frontal assessment battery: psychometric properties and normative data. Dement. Geriatr. Cogn. Disord. 29, 363-370. doi: 10.1159/000297523

Kopp, B., Rösser, N., Tabeling, S., Stürenburg, H. J., Haan, B., Karnath, H. O., et al. (2013). Performance on the Frontal Assessment Battery is sensitive to frontal lobe damage in stroke patients. BMC Neurol. 13:179. doi: 10.1186/1471-2377-13-179

Kugo, A., Teradaa, S., Ataa, T., Ido, Y., Kado, Y., Ishihara, T., et al. (2007). Japanese version of the Frontal Assessment Battery for dementia. Psychiatry Res. 153, 69-75. doi: 10.1016/j.psychres.2006.04.004

Kume, K., Hanyu, H., Murakami, M., Sato, T., Hirao, K., Kanetaka, H., et al. (2011). Frontal assessment battery and brain perfusion images in amnestic mild cognitive impairment. Geriatr. Gerontol. Int. J. 11, 77-82. doi: 10.1111/j.1447-0594.2010.00645.x

Larner, A. J. (2013a). Introduction to Cognitive "Screening instruments: rationale, desiderata, and assessment of utility," in Cognitive Screening Instruments: A Practical Approach, ed A. J. Larner (New York, NY: Springer), 1-15.

Larner, A. J. (2013b). Comparing diagnostic accuracy of cognitive screening instruments: a weighted comparison approach. Dement. Geriatr. Cogn. Disord. 3, 60-65. doi: 10.1159/000348623

Larson, E. B., and Heinemann, A. W. (2010). Rasch analysis of the Executive Interview (The EXIT-25) and introduction of an abridged version (The Quick EXIT). Arch. Phys. Med. Rehabil. 91, 389-394. doi: 10.1016/j.apmr.2009. 11.015

Larson, E. B., Duff, K. M., Leahy, B., and Wilde, M. (2008). Assessing executive functions in traumatic brain injury: an exploratory study of the executive interview. Percept. Mot. Skills 106, 725-736. doi: 10.2466/pms.106.3.725-736

Lee, J. H., Byun, M. S., Sohn, B. K., Choe, Y. M., Han, J. Y., Choi, H. J., et al. (2015). Functional neuronatomical correlates of the frontal assessment battery performance in Alzheimer Disease: a FDG-PET study. J. Geriatr. Psychiatry Neurol. 28, 184-192. doi: 10.1177/0891988715573533
Leh, S. E., Petrides, M., and Strafella, A. P. (2010). The neural circuitry of executive functions in healthy subjects and Parkinson's disease. Neuropsychopharmacology 35, 70-85. doi: 10.1038/npp.2009.88

Leslie, F. V., Foxe, D., Daveson, N., Flannagan, E., Hodges, J. R., and Piguet, O. (2015). FRONTIER Executive Screen: a brief executive battery to differentiate frontotemporal dementia and Alzheimer's disease. J. Neurol. Neurosurg. Psychiatry 87, 831-835. doi: 10.1136/jnnp-2015-311917

Lezak, M. D., Howieson, D. B., Bigler, E. D., and Tranel, D. (2012). Neuropsychological Assessment, 5th Edn. London: Oxford University Press.

Lima, C. F., Meireles, L. P., Fonseca, R., Castro, S. L., and Garret, C. (2008). The Frontal Assessment Battery (FAB) in Parkinson's disease and correlations with formal measures of executive functioning. J. Neurol. 255, 1756-1761. doi: 10.1007/s00415-008-0024-6

Lipton, A. M., Ohman, K. A., Womack, K. B., Hynan, L. S., Ninman, E. T., and Lacritz, L. H. (2005). Subscores of the FAB differentiate frontotemporal lobar degeneration from AD. Neurology 65, 726-731. doi: 10.1212/01.wnl.0000174437.73416.7b

Malloy, P. F., Cummings, J. L., Coffey, C. E., Duffy, J., Fink, M., Lauterbach, E. C., et al. (1997). Cognitive screening instruments in neuropsychiatry: a report of the Committee on Research of the American Neuropsychiatric Association. J. Neuropsychiatry Clin. Neurosci. 9, 189-197.

Marconi, R., Antonini, A., Barone, P., Colosimo, C., Avarello, T. P., Bottacchi, E., et al. (2011). Frontal assessment battery scores and nonmotor symptoms in parkinsonian disorders. Neurol. Sci. 33, 585-593. doi: 10.1007/s10072-011-0807-x

Mathuranath, P. S., Nestor, P. J., Berrios, G. E., Rakowicz, W., and Hodges, J. R. (2000). A brief cognitive test battery to differentiate Alzheimer's disease and frontotemporal dementia. Neurology, 55, 1613-1620. doi: 10.1212/wnl.55. 11.1613

Matioli, M. N., Caramelli, P., Marques, B. D., Rocha, F. D., Castro, M. C., Yamashita, S. R., et al. (2008). EXIT 25 - executive interview applied to a cognitively healthy elderly population with heterogeneous educational background. Dement. Neuropsychol. 2, 305-309. doi: 10.1590/S1980-57642009DN20400013

Matsui, H., Udaka, F., Miyoshi, T., Hara, N., Tamura, A., Oda, M., et al. (2006). Frontal assessment battery and brain perfusion image in Parkinson's Disease. J. Geriatr. Psychiatry Neurol. 19, 41-45. doi: 10.1177/0891988705284714

McGuiness, B., Barrett, S. L., Craig, D., Lawson, J., and Passmore, A. P. (2010). Executive functioning in Alzheimer's disease and vascular dementia. Int. J. Geriatr. Psychiatry, 25, 562-568. doi: 10.1002/gps.2375

Miyake, A., Freidman, N. P., Emerson, M. J., Witzki, A. H., and Howerter, A. (2000). The unity and diversity of executive functions and their contributions to complex "frontal lobe" tasks: a latent variable analysis. Cogn. Psychol. 41, 49-100. doi: 10.1006/cogp.1999.0734

Mok, V. C. T., Wong, A., Yim, P., Fu, M., Lam, W. W. M., Hui, A. C., et al. (2004). The validity and reliability of chinese frontal assessment battery in evaluating executive dysfunction among chinese patients with small subcortical infarct. Alzheimer Dis. Assoc. Disord. 18, 68-74. doi: 10.1097/01.wad.0000126617.54783.7

Moorhouse, P., Gorman, M., and Rockwood, K. (2009). Comparison of EXIT-25 and the frontal assessment battery for evaluation of executive dysfunction in patients attending a memory clinic. Dement. Geriatr. Cogn. Disord. 27, 424-428. doi: $10.1159 / 000212755$

Moreira, H., Lima, C., and Vicente, S. (2014). Examining Executive Dysfunction with the Institute of Cognitive Neurology (INCEO) Frontal Screening (IFS). normative values from a healthy sample and clinical utility in Alzheimer's Disease. J. Alzheimers Dis. 42, 261-273. doi: 10.3233/JAD-1 32348

Mujic, F., Lebovich, E., Von Heising, M., Clifford, D., and Prince, M. (2014). The Executive Interview (EXIT25) as a tool for assessing executive functioning in older medical and surgical inpatients referred to a psychiatry service: feasibility of creating a brief version. Int. Psychogeriatr. 26, 935-941. doi: $10.1017 /$ S104161021400026X

Nagata, T., Shinagawa, S., Ochiai, Y., Aoki, R., Kasahara, H., Nukariya, K., et al. (2011). Association between executive dysfunction and hippocampal volume in Alzheimer's disease. Int. Psychogeriatr. 23, 764-771. doi: $10.1017 /$ S1041610210002164 
Nakaaki, S., Murata, Y., Sato, J., Shinagawa, Y., Matsui, T., Tatsumi, H., et al. (2007). Reliability and validity of the Japanese version of the frontal assessment battery in patients with the frontal variant of frontotemporal dementia. Psychiatry Clin. Neurosci. 6, 78-83. doi: 10.1111/j.1440-1819.2007.01614.x

Nasreddine, Z. S., Phillips, N. A., Bédirian, V., Charbonneau, S., Whitehead, V., Collin, I., et al. (2005). The montreal cognitive assessment, MoCA: a brief screening tool for mild cognitive impairment. J. Am. Geriatr. Soc. 53, 695-699. doi: 10.1111/j.1532-5415.2005.53221.x

Oguro, H., Yamaguchi, S., Abe, S., Ishida, Y., Bokura, H., and Kobayashi, S. (2006). Differentiating Alzheimer's disease from subcortical vascular dementia with the FAB test. J. Neurol. 253, 1490-1494. doi: 10.1007/s00415-006-0251-7

Oshima, E., Terada, S., Sato, S., Nagao, S., Takeda, N., Honda, H., et al. (2012). Frontal assessment battery and brain perfusion imaging in Alzheimer's disease. Int. Psychogeriatr. 24, 994-1001. doi: 10.1017/S1041610211002481

Oskarsson, B., Quan, D., Rollins, Y. D., Neville, H. E., Ringel, S. P., and Arciniegas, D. B. (2010). Using the Frontal Assessment Battery to identify executive function impairments in amyotrophic lateral sclerosis: a preliminary experience. Amyotroph. Lateral Scler. 11, 244-247. doi: 10.3109/17482960903059588

Otero, T. M., and Barker, L. A. (2014). "The frontal lobes and executive functioning," in Handbook of Executive Functioning, eds S. Goldstein and J. A. Naglieri (New York, NY: Springer), 29-44.

Panksepp, J. (1998). Affective Neuroscience: The Foundations of Human and Animal Emotions. New York, NY: Oxford University Press.

Panksepp, J. (2003). At the interface of the affective, behavioral, and cognitive neurosciences: decoding the emotional feelings of the brain. Brain Cogn. 52, 4-14. doi: 10.1016/S0278-2626(03)00003-4

Paviour, D. C., Winterburn, D., Simmonds, S., Burgess, G., Wilkinson, L., Fox, N. C., et al. (2005). Can the frontal assessment battery (FAB) differentiate bradykinetic rigid syndromes? Relation of the FAB to formal neuropsychological testing. Neurocase 11, 274-282. doi: 10.1080/13554790590962933

Pellechia, M. T., Picillo, M., Santangelo, G., Longo, K., Moccia, M., Erro, R., et al. (2015). Cognitive performances and DAT imaging in early Parkinson's disease with mild cognitive impairment: a preliminary study. Acta Neurol. Scand. 131, 275-281. doi: 10.1111/ane.12365

Pereira, F. S., Yassuda, M. S., Oliveira, A. M., and Forlenza, O. V. (2008). Executive dysfunction correlates with impaired functional status in older adults with varying degrees of cognitive impairment. Int. Psychogeriatr. 20, 1104-1115. doi: 10.1017/S1041610208007631

Pertl, M. T., Benke, T., Zamarian, L., and Delazer, M. (2017). Effects of healthy aging and mild cognitive impairment on a real-life decision-making task. J. Alzheimers Dis. 58, 1077-1087. doi: 10.3233/JAD-170119

Pessoa, L. (2009). How do emotion and motivation direct executive control? Trends Cogn. Sci. 13, 160-166. doi: 10.1016/j.tics.2009.01.006

Peterson, E., and Welsh, M. C. (2014). The "Development of hot and cool executive functions in childhood and adolescence: are we getting warmer?" in Handbook of Executive Functioning, eds S. Goldstein and J. A. Naglieri (New York, NY: Springer), 45-65.

Piatella, M. C., Tona, F., Bologna, M., Sbardella, A., Formica, N., Petsas, N., et al. (2015). Disrupted resting-state functional connectivity in progressive supranuclear palsy. Am. J. Neuroradiol. 36, 915-921. doi: 10.3174/ajnr.A4229

Rahman, S., Sahakian, B. J., Hodges, J. R., Rogers, R. D., and Robbins, T. W. (1999). Specific cognitive deficits in mild frontal variant frontotemporal dementia. Brain 122, 1469-1493. doi: 10.1093/brain/122.8.1469

Ray, W. A., Taylor, J. A., Lichtenstein, M. J., and Meador, K. (1992). The nursing home behavior problem scale. J. Gerontol. Med. Sci. 47, 9-16. doi: 10.1093/geronj/47.1.M9

Reichenberg, A., Harvey, P. D., Bowie, C. R., Mojtabai, R., Rabinowitz, J., Heaton, R. K., et al. (2009). Neuropsychological function and dysfunction in schizophrenia and psychotic affective disorders. Schizophr. Bull. 35, 1022-1029. doi: $10.1093 /$ schbul/sbn044

Robinson, H., Calamia, M., Glascher, J., Bruss, J., and Tranel, D. (2014). Neuroanatomical correlates of executive functions: a neuropsychological approach using the EXAMINER battery. J. Int. Neuropsychol. Soc. 20, 52-63. doi: 10.1017/S135561771300060X

Rodrigues, G. R., Souza, C. P., Celtin, R. S., de Oliveira, D. S., Pena-Pereira, M., Ujikawa, L. T., et al. (2009). Use of the frontal assessment battery in evaluating executive dysfunction in patients with Huntington's disease. J. Neurol. 256, 1809-1815. doi: 10.1007/s00415-009-5197-0

Royall, D. R., Mahurin, R. K., and Cornell, J. (1994). Bedside assessment of frontal degeneration: distinguishing Alzheimer's Disease from Non-Alzheimer's Cortical Dementia. Exp. Aging Res. 20, 95-103. doi: 10.1080/03610739408253956

Royall, D. R., Mahurin, R. K., and Gray, K. F. (1992). Bedside assessment of executive cognitive impairment: the executive interview. J. Am. Geriatr. Soc. 40, 1221-1226. doi: 10.1111/j.1532-5415.1992.tb03646.x

Royall, D. R., Palmer, R., Chiodo, L. K., and Polk, M. J. (2004). Declining executive control in normal aging predicts change in functional status: the freedom house study. J. Am. Geriatr. Soc. 52, 346-352. doi: 10.1111/j.1532-5415.2004. 52104.x

Royall, D. R., Rauch, R., Román, G. C., Cordes, J. A., and Polk, M. J. (2001). Frontal MRI findings associated with impairment on the executive interview (EXIT 25). Exp. Aging Res. 27, 293-308. doi: 10.1080/03610730109342350

Sgaramella, T. M., Borgo, F., Mondini, S., Pasini, M., Toso, V., and Semenza, C. (2001). Executive deficits appearing in the initial stage of Alzheimer's disease. Brain Cogn. 46, 264-268. doi: 10.1016/S0278-2626(01)80080-4

Sinoff, G., Peer, D., Sivan, D., and Sela-Katz, P. (2001). EXIT 25: A brief instrument to diagnose frontal disturbances in elderly persons suffering from dementia: reliability and validity of the Hebrew version of this instrument. Gerontology 28, 71-86.

Slachevsky, A., Villapando, J. M., Sarazin, M., Hahn-Barma, V., Pillon, B., and Dubois, B. (2004). Frontal assessment battery and differential diagnosis of frontotemporal dementia and Alzheimer Disease. Arch. Neurol. 61, 1104-1107. doi: 10.1001/archneur.61.7.1104

Stokholm, J., Vogel, A., Gade, A., and Waldemar, G. (2006). Heterogeneity in executive impairment in patients with very mild Alzheimer's disease. Dement. Geriatr. Cogn. Disord. 22, 54-59. doi: 10.1159/000093262

Strauss, E., Sherman, E. M. S., and Spreen, E. (2006). A Compendium of Neuropsychological Tests: Administration, Norms, and Commentary, 3th Edn. New York, NY: Oxford University Press.

Swanberg, M. M., Tractenberg, R. E., Mohs, R., and Cummings, J. L. (2004). Executive dysfunction in Alzheimer disease. Arch. Neurol. 61, 556-560. doi: 10.1001/archneur.61.4.556

Tartaglia, M. C., Zhang, Y., Racine, C., Laluz, V., Neuhaus, J., Chão, L., et al. (2012). Executive dysfunction in frontotemporal dementia is related to abnormalities in frontal white matter tracts. J. Neurol. 259, 1071-1080. doi: 10.1007/s00415-011-6300-x

Tekin, S., Fairbanks, L. A., O'Connor, S., Rosenberg, S., and Cummings, J. L. (2001). Activities of daily living in Alzheimer's disease: neuropsychiatric, cognitive, and medical illness influences. Am. J. Geriatr. Psychiatry 8, 81-86. doi: 10.1097/00019442-200102000-00013

Torralva, T., Roca, M., Gleichgerrcht, E., López, P., and Manes, F. (2009). INECO Frontal Screening (IFS): a brief, sensitive, and specific tool to assess executive functions in dementia. J. Int. Neuropsychol. Soc. 15, 777-786. doi: 10.1017/S1355617709990415

Tunçay, N., Kayserili, G., Erhan, E., Akdede, B. B., Zorlu, Y., and Yener, G.(2008). Validation and reliability of the Frontal Assessment Battery (FAB) in Turkish. Front. Hum. Neurosci. 2:3. doi: 10.3389/conf.neuro.09.2009.01.379

Unterrainer, J. M., Rahm, B., Kaller, C. P., Ruff, C. C., Spreer, J., Krause, B. J., et al. (2004). When planning fails: individual differences and errorrelated brain activity in problem solving. Cerebral Cortex, 14, 1390-1397. doi: 10.1093/cercor/bhh100

Wild-Wall, N., Falkenstein, M., and Gajewski, P. D. (2011). Age-related differences in working memory performance in a 2-back task. Front. Psychol. 2:186. doi: 10.3389/fpsyg.2011.00186

Wilmsmeier, A., Ohrmann, P., Suslow, T., Siegmund, A., Koelkebeck, K., Rothermundt, M., et al. (2010). Neural correlates of set-shifting: decomposing executive functions in schizophrenia. J. Psychiatry Neurosci. 35, 321-329. doi: 10.1503/jpn.090181

Wilson, B. A., Alderman, N., Burguess, P. W., Emslie, H., and Evans, J. J. (1996). Behavioral Assessment of the Dysexecutive Syndrome. London: Thames Valley Test.

Yoon, J. H., Hoffman, J. N., and D'Esposito, M. (2007). Segregation of function in the lateral prefrontal cortex during visual object working memory. Brain Res. 1184, 217-225. doi: 10.1016/j.brainres.2007.09.074 
Yoshida, H., Terada, S., Sato, S., Kishimoto, Y., Ata, T., Ohshima, E., et al. (2009). Frontal assessment battery and brain perfusion imaging in early dementia. Dement. Geriatr. Cogn. Disord. 27, 133-138. doi: 10.1159/000198687

You, S. C., Geschwind, M. D., Sha, S. J., Apple, A., Satris, G., Wood, K. A., et al. (2014). Executive functions in premanifest Huntington's disease. Mov. Disord. 29, 405-409. doi: 10.1002/mds.25762

Zelazo, P. D., and Muller, U. (2002). "Executive functioning in typical and atypical development," in Handbook of Childhood Cognitive Development, ed U. Goswami. (Oxford: Blackwell), 445-469.
Conflict of Interest Statement: The authors declare that the research was conducted in the absence of any commercial or financial relationships that could be construed as a potential conflict of interest.

Copyright (๑) 2017 Moreira, Costa, Castro, Lima and Vicente. This is an open-access article distributed under the terms of the Creative Commons Attribution License (CC $B Y)$. The use, distribution or reproduction in other forums is permitted, provided the original author(s) or licensor are credited and that the original publication in this journal is cited, in accordance with accepted academic practice. No use, distribution or reproduction is permitted which does not comply with these terms. 